\title{
Parental age, genetic mutation, and cerebral palsy
}

\author{
N A Fletcher, J Foley
}

\begin{abstract}
Parental age and birth order were studied in 251 patients with cerebral palsy. No parental age or birth order effects were observed in spastic quadriplegia or diplegia, but a paternal age effect was detected in those with athetoid/ dystonic cerebral palsy and congenital hemiplegia. These observations indicate that some cases of athetoid/dystonic or hemiplegic cerebral palsy might arise by fresh dominant genetic mutation. (f Med Genet 1993;30:44-6)
\end{abstract}

Cerebral palsy $(\mathrm{CP})$ is characterised by aberrant control of movement or posture, appearing early in life (secondary to a central nervous system lesion, damage, or dysfunction) and not the result of a recognised progressive or degenerative brain disease. ${ }^{1} \mathrm{CP}$ is clinically heterogeneous with spastic, extrapyramidal (athetoid/dystonic), and ataxic subgroups. ${ }^{2}$ In contrast to earlier assumptions, birth asphyxia is now known to be a rare cause of CP. ${ }^{3}$ With mounting uncertainty about the importance of external perinatal influences, $\mathrm{CP}$ is increasingly regarded as a group of sporadic disorders of unknown aetiology. ${ }^{14}$

Similarly affected relatives are uncommon in the families of patients with CP. ${ }^{5}$ Excluding ataxic CP (which is frequently inherited) any genetic contribution to $\mathrm{CP}$ is thought to be small, ${ }^{6}$ although more likely if there are symmetrical physical signs. ${ }^{7}$ One hypothesis which might explain isolated cases of spastic or athetoid CP is fresh dominant genetic mutation. In autosomal dominant conditions where biological fitness is reduced, that is, affected subjects are less likely to reproduce (which seems likely in $\mathrm{CP}$ ), some cases must arise by mutation assuming that there is genetic equilibrium between a constant mutation rate and the effects of natural selection. ${ }^{8}$ If affected subjects rarely have children, the genetic basis of the condition may not be apparent. In this situation, the underlying cause may be suggested by an increased incidence of the disorder in later born sibs and those with older fathers, that is, an increased birth order and paternal age effect. ${ }^{9}$ This is because the probability of genetic mutation rises with paternal age owing to an increase in the number of cell divisions in spermatogenesis. $^{8}$

We have analysed birth order and parental age in 532 patients with spastic and athetoid $\mathrm{CP}$ in order to investigate the possible existence of cases arising by new dominant mutation.

\section{Methods}

All cases were ascertained from the records of the Cheyne Centre for Spastic Children, London. All had been referred from general practitioners or paediatricians in south-east England and were seen and examined personally by one of the authors (JF) between 1955 and 1986. CP was defined as above, low birth weight (LBW) as $<2500 \mathrm{~g}$, and prematurity as birth before 37 weeks' gestation.

Cases with recognisable syndromes or malformations, genetic or metabolic disorders, kernicterus, other identifiable causes for the motor disorder (including postnatal factors), similarly affected relatives, ataxic $\mathrm{CP}$, or asymmetrical quadriplegia were excluded.

The records of 532 cases were examined. Of these, 172 had spastic diplegia (65\% preterm, $69 \%$ LBW), 102 had congenital hemiplegia (23\% preterm, 20\% LBW), 104 had symmetrical spastic quadriplegia (26\% preterm, 35\% LBW), and 154 had athetoid/dystonic CP (14\% preterm, 19\% LBW). Sibship size, birth order, parental ages at the time of birth, and date of birth were recorded. Of the 532 cases, 399 were born in the UK to parents whose ages had been recorded; 251 of these were born between 1961 and 1983 which is the period for which the Registrar General has published annual mean parental ages for the UK population. ${ }^{10}$

Methods of birth order and parental age analysis were those described by Emery. ${ }^{11}$ Birth order was analysed using the method of Haldane and Smith. ${ }^{12}$ For each case, the observed birth order is recorded and the expected birth order and its variance (assuming no birth order effect) calculated from the sibship size and published tables. ${ }^{11}$ In each group of cases, the standard error of the difference between the sums of the observed and expected birth orders is the square root of the sum of the variances. Parental ages at the time of birth of each case were compared with mean UK population maternal and paternal ages for the corresponding year using paired $t$ tests. For each group of cases, mean differences between observed and expected values of paternal age $\left(d_{p}\right)$, maternal age $\left(d_{m}\right)$, and birth order $\left(d_{b}\right)$ were calculated.

As $d_{p}, d_{m}$, and $d_{b}$ are mutually dependent variables, a method based on regression analysis was used to compare any statistically significant value of one with that predicted by the observed values of the other two. ${ }^{113}$ The difference between observed and predicted values is $d_{1}-b_{12} d_{2}$, where $d_{1}$ is the mean increase in one of the three variables $\left(d_{p}, d_{m}\right.$, or $\left.d_{b}\right), d_{2}$ is the mean increase in one of the other two, and $b_{12}$ is a regression coefficient given by $s_{1} r_{12} / s_{2}$ 
where $s_{1}$ and $s_{2}$ are the standard deviations and $r_{12}$ is the product moment correlation coefficient of variables 1 and 2 in the population. Standard errors for these differences can be calculated as described by Smith. ${ }^{13}$ For these calculations, the following correlation coefficients were used: birth order and paternal age $=0.3$, birth order and maternal age $=0.45$, and maternal age and paternal age $=0 \cdot 72 .{ }^{11}$ Population standard deviations for paternal age ( 6.42 years), maternal age $(5.41)$, and birth order $(1.31)$ were assumed to be those in the Registrar General's statistics for $1970 .{ }^{11}$

\section{Results}

Of the 251 cases included, 50 had spastic quadriplegia, 49 hemiplegia, 75 diplegia, and 77 athetoid/dystonic CP. Parental age data for each group of patients are given in table 1 . In those with quadriplegia there was no significant increase in paternal age $\left(d_{p}=+0.99\right.$ years, $\mathrm{p}>0.2)$, maternal age $\left(\mathrm{d}_{\mathrm{m}}=+0.2\right.$ years, $p>0 \cdot 7)$, or birth order $\left(d_{b}=+0 \cdot 12, p>0 \cdot 1\right)$. In the diplegia group, paternal age $\left(d_{p}=+1 \cdot 27\right.$ years, $p>0.05)$, maternal age $\left(d_{m}=-0.33\right.$ years), and birth order $\left(d_{b}=+0 \cdot 18, p>0 \cdot 1\right)$ were also similar to those in the UK population. No significant paternal age effect was seen in the diplegia cases when preterm $(+1 \cdot 19$ years, $n=51)$ and term $(+1.45$ years, $n=24)$ births were analysed separately.

Significant parental age and birth order effects were seen in those with athetoid and hemiplegic CP and these data are shown in table 2 . In the hemiplegia group (table 2), birth order was not significantly increased after allowance for the observed increases in parental ages. Paternal age was not significantly increased after adjustment for the observed rise in maternal age and vice versa. However, the paternal age effect was greater and

Table 1 Parental age data.

\begin{tabular}{llccc}
\hline CP subgroup & & $\begin{array}{c}\text { Mean parental } \\
\text { age }(\mathrm{y})\end{array}$ & SD & Range \\
\hline Quadriplegia $(\mathrm{n}=50)$ & Paternal & $30 \cdot 2$ & $5 \cdot 74$ & $19-43$ \\
Diplegia $(\mathrm{n}=75)$ & Maternal & $27 \cdot 1$ & $4 \cdot 92$ & $19-38$ \\
& Paternal & $30 \cdot 7$ & $6 \cdot 73$ & $19-45$ \\
Athetoid $(\mathrm{n}=77)$ & Maternal & $26 \cdot 8$ & $6 \cdot 62$ & $16-45$ \\
& Paternal & $31 \cdot 4$ & $7 \cdot 33$ & $21-63$ \\
Hemiplegia $(\mathrm{n}=49)$ & Maternal & $28 \cdot 7$ & $6 \cdot 01$ & $18-44$ \\
& Paternal & $31 \cdot 5$ & $7 \cdot 12$ & $19-47$ \\
& Maternal & $28 \cdot 9$ & $6 \cdot 14$ & $18-41$ \\
\hline
\end{tabular}

Table 2 Parental age and birth order analysis in athetoid and hemiplegic CP.

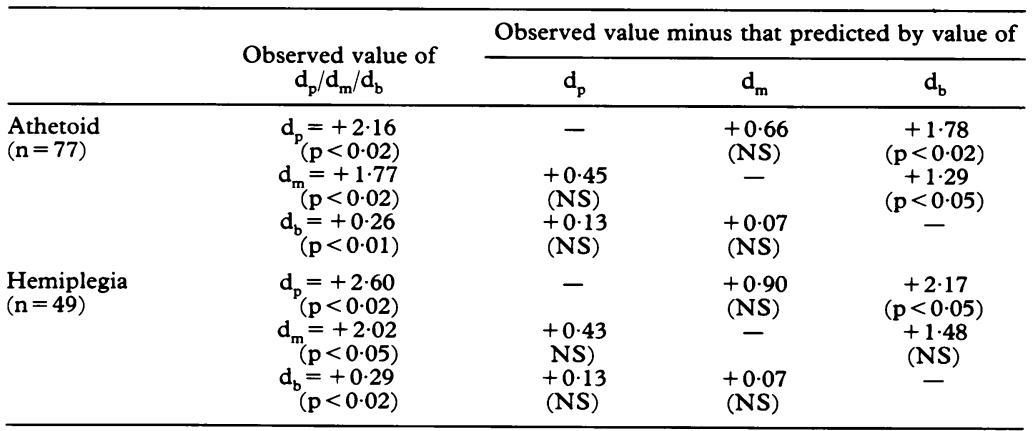
$d_{p}=$ paternal age effect, $d_{m}=$ maternal age effect, $d_{b}=$ birth order effect, $N S=$ not significant
$(p>0.05)$ remained (at the 0.05 level) after adjustment for the observed rise in birth order, while this was not so for maternal age.

In the athetoid/dystonic CP cases (table 2), a birth order effect also disappeared after allowing for either parental age effect. Although neither parental age increase was significant after correction for the other, there was a highly significant difference between the paternal age effect and that predicted by the rise in birth order, while this was barely significant for maternal age.

\section{Discussion}

Until recently, CP was thought to be caused by adverse perinatal factors, especially hypoxicischaemic damage. ${ }^{1}$ This has been accepted particularly in athetoid/dystonic CP. ${ }^{14} \mathrm{Al}-$ though some prenatal and perinatal risk factors are associated with the subsequent development of CP, many of these are not specific to asphyxia, ${ }^{15}$ not necessarily causative, and absent in the majority of children with CP. Moreover, the majority of those in whom such risk factors are present develop normally. ${ }^{1}$

To test our hypothesis that some isolated cases of spastic or athetoid/dystonic CP arise because of genetic mutation, we have tried to determine whether paternal age among cases is higher than in the normal population. A serious difficulty in birth order and parental age studies arises from the interrelationship between the three variables; a change in one is associated with an alteration of one or both of the others. All statistical approaches to this difficulty are open to methodological criticism $^{1113}$ and it may be difficult or impossible to establish which variable is increased because of an association with the cause of a disorder. ${ }^{11}$ In this study, birth order and parental age are significantly increased only among cases aith athetoid/dystonic CP and congenital hemiplegia. In athetoid/dystonic CP, maternal and paternal age are still increased after allowing for birth order but the paternal age increase is more significant. Therefore, a paternal age effect seems more likely than a maternal one. In the hemiplegia group, the paternal age effect is just significant after birth order is taken into account. The results indicate a paternal age effect in athetoid/dystonic CP and possibly in hemiplegic CP.

There are other reasons for doubting that increased maternal age is the more important factor. CP is thought to be related to parity or maternal age in a similar way to perinatal mortality. ${ }^{16}$ The latter is associated with younger (less than 20 years) as well as older (over 34 years old) mothers and is higher in first born infants than in later birth orders, only rising again with high parities of five or more. ${ }^{1718}$ An association between total CP and increased maternal age was noted in an earlier series, ${ }^{19}$ but paternal age was not examined; consequently this could have been secondary to a paternal age effect.

A genetic contribution to the causation of $\mathrm{CP}$ has long been suspected; several genetic disorders may resemble CP clinically ${ }^{2021}$ and 
ataxic CP (with a normal birth history) is now thought to be an autosomal recessive disorder in between a third and a half of cases. ${ }^{6}$ Spasticity, if symmetrical, is sometimes familial with empirical recurrence risks for sibs of around $10 \%{ }^{7}$ Extrapyramidal CP owing to $X$ linked inheritance has been described ${ }^{22}$ although this family had many features of Pelizaeus-Merzbacher disease. Affected sibs, possibly reflecting recessive or $X$ linked inheritance, have been reported in athetoid/dystonic $\mathrm{CP}^{7202324}$ and recurrence risks for sibs may be as high as $10 \%$ if signs are symmetrical and birth history normal. Whether the normal birth history criterion is any longer valid in the light of recent studies of perinatal factors in CP is uncertain.

The presence of a paternal age effect in athetoid/dystonic CP suggests that some apparently isolated cases may be the result of new genetic mutation ${ }^{9}$; this may apply to hemiplegic $\mathrm{CP}$ but the evidence in this group is weaker. Athetoid/dystonic and hemiplegic $\mathrm{CP}$ are clinically and pathologically heterogeneous $^{42-27}$ so that cases resulting from new genetic mutations may only be a subgroup. However, the existence of paternally derived $\mathrm{CP}$ mutations is an intriguing possibility in the light of the apparently vascular basis of some pathological lesions in athetoid/dystonic CP and hemiplegia. ${ }^{28}$ Owing to genomic imprinting effects, paternal genes are critical for the development and maintenance of the placenta. ${ }^{29}$ Could placental dysfunction as a result of a paternally derived genetic mutation cause fetal cerebrovascular damage leading directly (or in combination with otherwise insufficient intrapartum factors) to athetoid/dystonic CP and possibly congenital hemiplegia? If fresh dominant mutation does cause some cases of athetoid/dystonic CP, reduced biological fitness (which seems likely) and some affected children would be predicted. Careful family studies with unbiased ascertainment, examination of offspring, and estimation of reproductive fitness of CP patients would be a useful means of studying this issue further.

We are grateful to the Queen Square Development Foundation for financial support and to
Professor N Morton and Professor C A B Smith for valuable discussion.

1 Russman BS, Gage JR. Cerebral palsy. Curr Prob Paediatr 1989;19:67-111.

2 Ingram TTS. The epidemiology of the cerebral palsies. Clin Dev Med 1984;87:1-12.

3 Nelson KB, Ellenberg JH. Antecedents of cerebral palsy: multivariate analysis of risk. $N$ Engl f Med 1986;315:81-6.

4 Foley J. Dyskinetic and dystonic cerebral palsy and birth. Acta Paediatr 1992;81:57-60.

5 Asher P, Schonell FE. A survey of 400 cases of cerebral palsy in childhood. Arch Dis Child 1950;25:360-79.

6 Baraitser M. The genetics of neurological disorders. Oxford: Oxford University Press, 1990: 75-7.

7 Bundey S, Griffiths MI. Recurrence risks in families of children with symmetrical spasticity. Dev Med Child Neurol 1977;19:179-91.

8 Vogel F, Motulsky AG. Human genetics. 2nd ed. Berlin: Springer 1986:355-61.

9 Penrose LS. Parental age and mutation. Lancet 1955;ii:3123.

10 Office of Population Censuses and Surveys. Series FM1, No 13. Birth statistics 1837-1983. Historical series. LonNo 13. Birth statistics
don: HMSO, 1987.

11 Emery AEH. Methodology in medical genetics. An introduction to statistical methods. 2nd ed. Edinburgh: Churchill Livingstone, 1986:141-53.

12 Vogel F, Motulsky AG. Human genetics. 2nd ed. Berlin: Springer, 1986:651-3.

13 Smith CAB. Note on the estimation of parental age effects. Ann Hum Genet 1972;35:337-42.

14 Kyllerman M. Dyskinetic cerebral palsy. II. Pathogenetic risk factors and intrauterine growth. Acta Paediatr Scand risk factors and

15 Naeye RL, Peters EC, Bartholomew M, Landis JR. Origins of cerebral palsy. Am $\mathcal{F}$ Dis Child 1989;143:1154-61.

16 Stanley F. Social and biological determinants of the cerebral palsies. Clin Dev Med 1984;87:69-86.

17 Registrar General (Scotland). Annual Report, 1978 (parts 1 and 2).

18 Forfar JO. Demography, vital statistics and the pattern of disease in childhood. In: Forfar JO, Arneil GC, eds. Textbook of paediatrics. Edinburgh: Churchill Livingstone, 1984:1-25.

19 Ingram TTS. Paediatric aspects of cerebral palsy. Edinburgh: Churchill Livingstone, 1964

20 Fisher RL, Russman BS. Genetic syndromes associated with cerebral palsy. Clin Orthop Rel Res 1974;99:2-11.

21 Bundey S. Genetics and neurology. Edinburgh: Churchill Livingstone, 1985:251-3.

22 Baar HS, Gabriel AM. Sex linked spastic paraplegia. $A m \mathcal{F}$ Ment Defic 1966;71:13-8.

23 Christensen E, Melchior JC. Cerebral palsy - a clinical and pathological study. Clin Dev Med 1967;25.

24 Adler E. Familial cerebral palsy. F Chron Dis 1961;13:20714.

25 Kyllerman M, Bager B, Bensch J, et al. Dyskinetic cerebral palsy. I. Clinical categories, associated neurological abnormalities and incidences. Acta Paediatr Scand 1982;71:543-50.

26 Foley J. The athetoid syndrome: a review of a personal series. F. Neurol Neurosurg Psychiatry 1983;46:289-98.

27 Menkes JH. A textbook of child neurology. Philadelphia: Lea and Febiger, 1990:304-6.

28 Friede RL. Developmental neuropathology. 2nd ed. New York: Springer Verlag, 1989:83-97.

29 Hall JG. Genomic imprinting: review and relevance to human diseases. Am $\mathcal{f}$ Hum Genet 1990;46:857-73. 